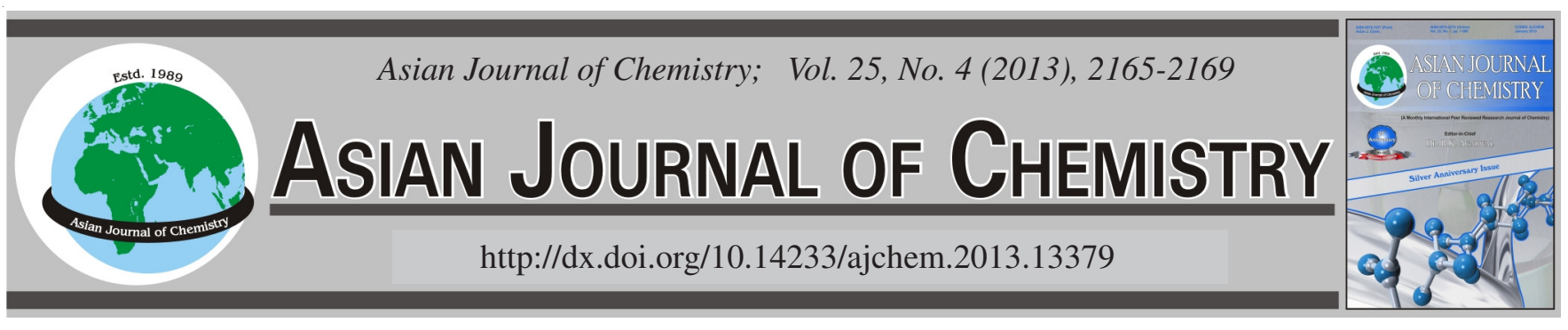

\title{
Comparative Analysis of in vitro Antioxidant Activity of Two Selected Plants With a Reference to Antidiabetic Profile
}

DiLipkUMAR PAL

Department of Pharaceutical Sciences, Guru Ghazidas Viswavidyalaya, Koni, Bilaspur-495 009, India

Corresponding author: Tel: +91 3244 243265; E-mail: drdilip2003@yahoo.co.in; drdilip71@gmail.com

(Received: 3 January 2012;

Accepted: 17 October 2012)

AJC-12304

\begin{abstract}
The antioxidant and antidiabetic activity of aerial parts of Aerva sanguinolenta (L) Blume and leaves of Mikania scandens (L.) Willd were investigated by three in vitro and one in vivo assays i.e., by estimating degree of non-enzymatic haemoglobin glycosylation measured colorimetrically at $520 \mathrm{~nm}$; by assaying DPPH free radical scavenging activity; by reduction of phosphomolybdenum complex and by estimating blood glucose levels in alloxan-induced diabetic mice. From the analysis, it was found that the ethyl acetate and chloroform extract of both aerial parts of A. sanguinolenta and leaves of Mikania scandens had higher antioxidant potential than that of other extracts of the plant(s). Among the examined plants, it was also observed that $M$. scandens L. extracts had better antioxidant and antihyperglycemic action than that of $A$. sanguinolenta. The antioxidant activity of the extracts was close, identical in magnitude, concentration dependent and comparable to that of standard antioxidant compounds used. Flavonoids and tannins present in the selected extracts may be responsible for such antioxidant and antidiabetic activities.
\end{abstract}

Key Words: Antioxidant and antidiabetic activity, Aerva sanguinolenta, Mikania scandens, Non-enzymatic haemoglobin glycosylation, DPPH free radical scavenging activity, Phosphomolybdenum complex.

ᄂ - - - - - - - - - - - - - - - - - - - - - - - - - - -

\section{INTRODUCTION}

The role of free radicals and active oxygen in the pathogenesis of human diseases including diabetes, cancer, aging, inflammation, metabolic disorders, reperfusion damage and atherosclerosis have been recognized ${ }^{1,2}$. Electron acceptors, such as molecular oxygen, make reaction rapidly with free radicals to form radicals themselves, also known as reactive oxygen species (ROS). The ROS involve hydrogen peroxide $\left(\mathrm{H}_{2} \mathrm{O}_{2}\right)$, superoxide anions $\left(\mathrm{O}_{2}^{-}\right)$and hydroxyl radicals $\left(\mathrm{OH}^{-}\right)^{3}$. Lipid peroxidation that includes a series of free radical related chain reactions is also associated with different types of biological disorders. Therefore, much importance has been provided on the use of antioxidants, particularly natural antioxidants to prevent lipid peroxidation, to scavenge free radicals and to improve health in oxidative stress-related disorders.

In recent years, phytochemicals are increasingly purported to exert potent beneficial actions to support health and economical viability and may play an important role in substituting synthetic drug use for the treatment of serious metabolic complications. To this effect, research has been concentrated on the identification of indigenous plants, herbs and spices and isolation of active compounds from natural resources with high antioxidant capacities ${ }^{4-9}$. The majority of the active antioxidants include flavonoids, isoflavonoids, flavones, anthocyanins, coumarins, catechins, isocatechins, jignans, tannins, polyphenolic compounds. Additionally, some compounds found in natural foods, vitamin $\mathrm{C}$ and $\mathrm{E}, \beta$-carotene and tocopherol are known to have good antioxidant properties. As antidiabetic activity is closely related with antioxidant activity, in this communication we have also investigated anti-hyperglycemic effects in mice. With this background and abundant source of unique active components harbored in plants, the present investigations were taken up on the selected plants namely Aerva sanguinolenta (L) Blume and Mikania scandens L. Willd.

Aerva sanguinolenta Blume (L) (Amaranthaceae; Lankaberi or lalpata in Bengali) is a large genus of annual or perennial clambering shrub or subshrub having stem erect, leaves alternate or opposite, margin entire, flowers perfect, unisexual or dioecious, small, inflorescences spikes, terminal or axilary, ovary-ovovoid, glabrous, style persistent; seeds reniform-orbicular, lenticular, compressed distributed in coastal areas of India ${ }^{10}$, Africa and China. There are approximately 70 genera and 900 species found worldwide and 15 genera and 44 species are found in china. Various parts of the plant have been used by tribes as bitter, astringent, cooling, emollient, vermifuge, suppurative, diuretic and lithontriptic ${ }^{11,12}$. It is used to treat boils, cephalagia, cough, stanguary, lithiasis, mental 
abnormalities and gynecological disorders. It has also good antibacterial and antiulcer activities ${ }^{13}$.

Mikania scandens (L.) Willd. (family: Asteraceae) a wild, a twining herb with long petiole, opposite leaves and small homogamous flower-heads grows as weed in all areas in India and Bangladesh ${ }^{14}$. It is used sometimes by men as vegetables. The plant is a good source of vitamin A, C, B and other active compounds like mikanin, sesquiterpenes, betasitosterin, stigmasterol, friedelin ${ }^{15,16}$. Various parts of this plant have been used in tribal medicine to treat stomach ulcers, gastric problems, inflammation, microbial infections and carcinogenic manifestations. The plant is also reported in traditional medicine to have psychopharmacological effects ${ }^{17,18}$.

\section{EXPERIMENTAL}

Haemoglobin was purchased from Nice Chemicals Pvt. Ltd., Cochin. Glucose, phosphate buffer and D- $\alpha$-tocopherol were procured from Merck, Mumbai. Ascorbic acid and gentamycin were obtained from Biokem International Pvt. Ltd., Bangalore and Nicholas Piramol India Ltd. Pithampur, respectively. 1,1-Diphenyl-2-picrylhydrazyl (DPPH) was purchased from Sigma Chemicals Co. (St. Louis, MO, USA). Ammonium molybdate was obtained from POCh (Gliwice, Poland). Alloxan monohydrate and glibenclamide were obtained from SD Fine Chemicals, India and Sun Pharma, India, respectively. All other reagents and solvents used were of analytical grade.

Thirty six albino mice of either sex ( $22 \pm 2 \mathrm{~g}$; Swiss strain) were obtained from B.N. Ghosh \& Company, India and screened for the present study. The animals were fed standard pellet diet (Hindustan Lever Ltd., India) consisting of vitamin mixture $(1 \%)$, mineral mixture $(4 \%)$, corn oil (10\%), sucrose $(20 \%)$, cellulose $(0.2 \%)$, casein $95 \%$ pure $(10.5 \%)$, starch $(54.3 \%)$ and water was provided ad libitum. The experimental design was subjected to the scrutiny of Institutional Ethical Committee. The animals were handled as per the guidance of the Committee for the Purpose of Control and supervision on Experimental animals (CPCSEA), New Delhi, India. All efforts were made to minimize both the suffering and number of animals used.

Preparation of extracts: Fresh aerial parts of $A$. sanguinolenta (L) Blume and leaves of M. scandens (L.) Willd were collected locally from North 24 PGS and East Midnapore district of West Bengal, India in the month of September and November, respectively as these contain the maximum active constituents at that time. These were authenticated by Dr. H.J. Chowdhury, Joint Director, Central National Herbarium, Botanical Survey of India, Howrah, West Bengal, India. The voucher specimens (DKS 09/2009 and DKJ 10/2009) have been submitted to IFTM University herbarium for further reference. After collection plant parts were washed properly with water to remove foreign materials.

The shade dried plant parts of A. sanguinolenta and $M$. scandens was separately powdered, sieved (40 mesh size) and extracted successively with petroleum ether $\left(40-60{ }^{\circ} \mathrm{C}\right)$, chloroform, ethyl acetate, ethanol and water using a Soxhlet extractor. The extracts were concentrated to dryness in vacuum. The yield of petroleum ether, chloroform, ethyl acetate, ethanol and aqueous extract of $A$. sanguinolenta were 2.5, 2.0, 2.3, 3.5 and $5 \% \mathrm{w} / \mathrm{w}$, respectively. Similarly, the yield of petroleum ether, chloroform, ethyl acetate, ethanol and aqueous extract of $M$. scandens were 3.7, 2.8, 10.2, 14.5 and $12.5 \% \mathrm{w} / \mathrm{w}$, respectively with respect to dry starting materials.

Qualitative tests for the extracts and isolation: $A$. sanguinolenta on preliminary phytochemical analysis was found to contain alkaloids (chloroform, ethanol and aqueous extract), steroids (petroleum ether, ethyl acetate extract), flavonoids (ethyl acetate extract) tannin \& polyphenolic compounds (ethanol extract), saponin (aqueous extract). $M$. scandens on qualitative analysis gave positive tests for steroids (petroleum ether, ethyl acetate extract), terpenoid (petroleum ether extract), alkaloids (chloroform, ethyl acetate, aqueous extract), flavonoids (chloroform, ethyl acetate, ethanol extract) ${ }^{19,20}$. The extracts were subjected to antioxidant studies.

Antioxidant studies: Evaluation of the antioxidant activity of any drug sample or herbal extract can be carried out either by in vitro or in vivo models. Here, the evaluation was carried out by in vitro by (i) non-enzymatic glycosylation of haemoglobin and (ii) assaying DPPH free radical scavenging activity (iii) by reduction of phosphomolybdenum complex.

Non-enzymatic haemoglycosylation method: Since non-enzymatic glycosylation of haemoglobin is an oxidation reaction, an antioxidant is expected to inhibit the reaction. The antioxidant activities of different extracts were investigated by estimating degree of non-enzymatic haemoglobin glycosylation measured colorimetrically. Haemoglobin, 60 $\mathrm{mg} / 100 \mathrm{~mL}$ in $0.01 \mathrm{M}$ phosphate buffer (pH 7.4) was incubated in presence of $2 \mathrm{~g} / 100 \mathrm{~mL}$ concentration of glucose for $72 \mathrm{~h}$ in order to find out the best condition for haemoglobin glycosylation. The assay was performed by adding $1 \mathrm{~mL}$ of glucose solution, $1 \mathrm{~mL}$ of haemoglobin solution and $1 \mathrm{~mL}$ of gentamycin $(20 \mathrm{mg} / 100 \mathrm{~mL})$ in $0.01 \mathrm{M}$ phosphate buffer $(\mathrm{pH}$ 7.4). The mixture was incubated in dark at room temperature for $72 \mathrm{~h}$. The degree of glycosylation of hemoglobin in the presence of different concentration of extracts and their absence were measured colorimetrically at $520 \mathrm{~nm}^{21,22}$.

Method of DPPH free radical scavenging activity: $7.886 \mathrm{mg}$ of DPPH was accurately weighed and dissolved in $100 \mathrm{~mL}$ methanol to obtain $200 \mu \mathrm{M}$ solution of DPPH. All the sample solutions were prepared against two concentrations, i.e., 0.5 and $1.0 \mathrm{mg} / \mathrm{mL}$.

To a $2 \mathrm{~mL}$ methanolic solution of DPPH, $2 \mathrm{~mL}$ sample solution was added. This mixture was incubated at room temperature in dark for $15 \mathrm{~min}$. The degree of free radical scavenging activity in the presence of different concentrations of extracts and their absence were measured colorimetrically at $517 \mathrm{~nm}$. The degree of free radical scavenging activity was denoted by:

DPPH radical - scavenging $(\%)=\left[\frac{\mathrm{A}_{\text {Control }}-\mathrm{A}_{\text {Sample }}}{\mathrm{A}_{\text {Control }}}\right] \times 100$ where $\mathrm{A}_{\text {Control }}=$ absorbance of DPPH alone, $\mathrm{A}_{\text {Sample }}=$ absorbance of DPPH with different concentration of extracts.

The $\mathrm{IC}_{50}$ value is the concentration of drug/extract required for $50 \%$ inhibition which is calculated from inhibition data and probit analysis for each extract. A lower $\mathrm{IC}_{50}$ value indicates greater antioxidant activity ${ }^{23,24}$. 


\begin{tabular}{llcl}
\hline \multicolumn{4}{c}{ EXTRACTION AND PHYTOCHEMICAL ANALYSIS OF DIFFERENT EXTRACTS OF A. sanguinolenta AND M. scandens } \\
\hline \multicolumn{1}{c}{ Extracts } & \multicolumn{4}{c}{ Nature } & Yield (\%) & Phytochemical analysis \\
\hline \multicolumn{4}{c}{ A. sanguinolenta } \\
\hline Petroleum ether extract & Greenish yellow solid & 2.5 & Steroids \\
Chloroform extract & Green solid & 2.0 & Alkaloids, steroids \\
Ethyl acetate extract & Brownish dark solid & 2.3 & Steroid, flavonoids, tannins \\
Ethanol extract & Deep brownish black solid & 3.5 & Alkaloid, tannin and polyphenolic compound \\
Aqueous extract & Reddish brown dark solid & 5.0 & Alkaloid, saponin \\
\hline & & M. scandens & \\
\hline Petroleum ether extract & Yellowish green solid & 3.7 & Steroids, terpenoids \\
Chloroform extract & Greenish solid & 2.8 & Alkaloids, flavonoids \\
Ethyl acetate extract & Greenish dark solid & 10.2 & Alkaloids, steroids, flavonoids,tannins \\
Ethanol extract & Reddish brown solid & 14.5 & Saponin, tannins and polyphenolic compound, flavonoids \\
Aqueous extract & Reddish black solid & 12.5 & Saponin, tannins and polyphenolic compound, alkaloids \\
\hline
\end{tabular}

Antioxidant potential assay: The antioxidant power of the extracts were assessed with the phosphomolybdenum reduction assay ${ }^{25,26}$. The reagent solution containing ammonium molybdate $(4 \mathrm{mM})$, sodium phosphate $(28 \mathrm{mM})$ and sulfuric acid $(600 \mathrm{mM})$ was mixed with the respective extract separately diluted with methanol in different concentrations, i.e., 0.25 , $0.50,0.75,1.0 \mathrm{mg} / \mathrm{mL}$. The samples were then kept for $1 \mathrm{~h}$ at $40^{\circ} \mathrm{C}$ or $90^{\circ} \mathrm{C}$ for incubation and the absorbance was measured at $695 \mathrm{~nm}$ for the green phosphomolybdenum complex formed. The reducing capacities of the extracts are expressed as the ascorbic acid equivalents.

Evaluation of antidiabetic activity in albino mice: On preliminary pharmacological screening, CEAS, EAAS and CEMS, EAMS showed significant antidiabetic activity in comparison to other extracts. Hence, these four extracts were taken for the evaluation of antidiabetic activity in mice. For this, CEAS, EAAS and CEMS, EAMS was dissolved in normal saline separately to prepare dose level of $150 \mathrm{mg} / \mathrm{kg} /$ body weight to administer in mice. Diabetes was induced in mice by a single intravenous injection of aqueous alloxan monohydrate $(150 \mathrm{mg} / \mathrm{kg}, \text { i.v. })^{27,28}$. After $48 \mathrm{~h}$, mice having serum glucose level above $200 \mathrm{mg} / \mathrm{dl}$ (diabetic) were selected for this study. The diabetic mice were divided into six groups each group containing six mice: Group I-Vehicle (normal saline, $5 \mathrm{~mL} / \mathrm{kg}$, p.o.), Group II-Glibenclamide (10 mg/kg, p.o.), Group III, IV, V and VI -CEAS, EAAS, CEMS and EAMS at the dose of $150 \mathrm{mg} / \mathrm{kg}$, p.o. in all cases. Dose was selected on consideration of acute toxic dose for each extract.

Blood samples were collected by cutting the tail at 0,2 , 4, 6, 8 and $24 \mathrm{~h}$, after administration of vehicle, glibenclamide and extract. Blood glucose levels were checked by Glucometer (Dr Morepen, 9F, 31 code).

Statistical analysis: Students't test was used for the statistical analyses of the results for antioxidant studies. All experiments were done in triplicate. For evaluation of antidiabetic activity, comparison between the test groups with control was made by one way analysis of variance (ANOVA), followed by Dunnett's ' $t$ ' test. Results for antidiabetic activity were expressed as mean arithmetic values \pm SD. $p<0.05$ was considered as significant in all cases.

\section{RESULTS AND DISCUSSION}

The percentage yield, nature of different extracts and results of qualitative tests are presented in Table-1. Again, the results of antioxidant activities of aerial parts of $A$. sanguinolenta and leaves of $M$. scandens L. extracts by non-enzymatic haemoglycosylation method are summarized in Table-2. The results indicated that in both the plant, ethyl acetate extract had highest (28.7, 52.2 and 35.2, $68.8 \%$, respectively) and aqueous extract had the lowest $(6.6,13$ and $7.6,14.7 \%$, respectively) antioxidant activity. In both cases chloroform extract exhibited good antioxidant activity $(15.5,30.9$ and 17.5, $33.9 \%$, respectively). It was also observed that in comparison, M. scandens L. extracts gave better antioxidant activity than that of $A$. sanguinolenta extracts. The activities were compared with D- $\alpha$-tocopherol (vitamin E) $(11,16.9 \%)$ and ascorbic acid (vitamin C) $(5.8,10 \%)$ which were used as standard antioxidant compounds.

\begin{tabular}{|c|c|c|}
\hline \multirow{3}{*}{ Samples } & \multicolumn{2}{|c|}{$\begin{array}{l}\text { TABLE-2 } \\
\text { ACTIVITIES OF DIFFERENT } \\
\text { Sanguinolenta AND M. scandens }\end{array}$} \\
\hline & \multicolumn{2}{|c|}{$\begin{array}{l}\text { Final concentration of the } \\
\text { tested compound }(\mathrm{mg} / \mathrm{mL})\end{array}$} \\
\hline & 0.5 & 1.0 \\
\hline \multicolumn{3}{|c|}{ A. sanguinolenta } \\
\hline PEAS & $7.1 \pm 0.16$ & $13.6 \pm 0.26$ \\
\hline CEAS & $15.5 \pm 0.32$ & $30.9 \pm 0.55$ \\
\hline EAAS & $28.7 \pm 0.40$ & $52.2 \pm 0.63$ \\
\hline EEAS & $8.0 \pm 0.30$ & $16.4 \pm 0.35$ \\
\hline AEAS & $6.6 \pm 0.28$ & $13.0 \pm 0.22$ \\
\hline \multicolumn{3}{|c|}{ M. scandens } \\
\hline PEMS & $16.1 \pm 0.36$ & $31.0 \pm 0.50$ \\
\hline CEMS & $17.5 \pm 0.38$ & $33.9 \pm 0.55$ \\
\hline EAMS & $35.2 \pm 0.53$ & $68.8 \pm 0.85$ \\
\hline EEMS & $10.8 \pm 0.30$ & $19.4 \pm 0.35$ \\
\hline AEMS & $7.6 \pm 0.25$ & $14.7 \pm 0.32$ \\
\hline D- $\alpha$ - tocopherol & $11.0 \pm 0.28$ & $16.9 \pm 0.34$ \\
\hline Ascorbic acid & $5.8 \pm 0.13$ & $10.0 \pm 0.21$ \\
\hline \multicolumn{3}{|c|}{$\begin{array}{l}\text { Percent inhibition of haemoglobin glycosylation was measured at two } \\
\text { concentrations of petroleum ether (PEAS), chloroform (CEAS), ethyl } \\
\text { acetate (EAAS), ethanol (EEAS), aqueous (AEAS) extract of A. } \\
\text { Sanguinolenta and petroleum ether (PEMS), chloroform (CEMS), } \\
\text { ethyl acetate (EAMS), ethanol (EEMS), aqueous (AEMS) extract of } \\
M \text {. Scandens. The activities were compared with those of D- } \alpha \text { - } \\
\text { tocopherol and ascorbic acid. Values are mean } \pm \text { SEM of three } \\
\text { replicates. * } p<0.001 \text { (considered highly significant) in comparison } \\
\text { with control group. }\end{array}$} \\
\hline
\end{tabular}

The DPPH (1,1-diphenyl-2-picrylhydrazyl) radical scavenging activity of $A$. sanguinolenta and $M$. scandens was found concentration dependent, i.e., increasing the concentration, 
higher the activity. DPPH has the advantage of being unaffected by certain side reactions, such as metal ion, chelation and enzyme inhibition. DPPH antioxidant analysis is based on the capacity of 1,1-diphenyl-2-picrylhydrazyl (DPPH), a stable free radical, to decolorize in the presence of antioxidants. DPPH radical contains an odd electron, which is responsible for the absorbance at $517 \mathrm{~nm}$ and also for a deep purple colour. When DPPH absorbs an electron donated by any antioxidant, the DPPH is decolorized/bleached resulting in a decrease in absorbance at $517 \mathrm{~nm}$. Hence, the more rapidly the absorbance decreases, the more potent the antioxidant activity of the extract. From the radical scavenging values of different extracts, it is clear that ethyl acetate and ethanol extract of $A$. sanguinolenta and $M$. scandens showed maximum scavenging effects (33.5, 65.4 and 33.3, 63.85\%), respectively. But in both cases petroleum ether extract showed lowest $(10.5,23$ and 15.8, $32 \%$, respectively) antioxidant activity. Ethyl acetate extract of $M$. scandens and chloroform extract of A. sanguinolenta also produced significant $(32.1,63$ and $27.1,52.7 \%$, respectively) DDPH scavenging activity in comparison to that of standard antioxidants used (ascorbic acid, D- $\alpha$-tocopherol) (32, 65.8 and 24.5, $49.3 \%$, respectively).

In phosphomolybdenum assay method, all extracts showed concentration dependent activity at 40 and $90^{\circ} \mathrm{C}$. The activity was greatest in ethyl acetate extract in both the plants in both incubation temperatures as determined by the intensity of the absorbance in tested concentrations. For other extracts the sequence of decreasing reducing capacity differed at $90{ }^{\circ} \mathrm{C}$. At $90^{\circ} \mathrm{C}$ the sequence was: ethyl acetate (strongest), then chloroform, ethanol, petroleum ether, aqueous extract (weakest) for both plants. But at $40^{\circ} \mathrm{C}$, the order was different:ethyl acetate, chloroform, petroleum ether, ethanol, aqueous extract (for $A$. sanguinolenta) and ethyl acetate, ethanol, petroleum ether, chloroform, aqueous extract (for $M$. scandens). The results were compared with standard antioxidants used (rutin, ascorbic acid). The results are reported in Table- 3 .

On observation of the effects of CEAS, EAAS and CEMS, EAMS on serum glucose level in alloxan-induced diabetic mice, it was found that administration of CEAS, EAAS and CEMS, EAMS (150 mg/kg. p.o.) in diabetic swiss albino mice showed reduction in serum glucose level after 2, 4, 6 and $8 \mathrm{~h}$ interval. Maximum reduction in serum glucose level was found after $4 \mathrm{~h}$ of administration of extract. Glibenclamide (10 $\mathrm{mg} / \mathrm{kg}$, p.o.) showed highest reduction from $208.2 \mathrm{mg} / \mathrm{dl}$ to
$178.1 \mathrm{mg} / \mathrm{dl}$ after $02 \mathrm{~h}$ in the same experimental design. It was also found that CEMS and EAMS showed comparatively better antidiabetic activity than CEAS and EAAS in the same dose level of treatment in diabetic mice.

Ethyl acetate and chloroform extract of both the plants (CEAS, EAAS and CEMS, EAMS, respectively) exhibited highest free radical scavenging and antioxidant properties in all assay procedures. However, the efficiency of other extracts differed depending on the particular assay methodology, reflecting the mechanism of action involved in total antioxidant capacity. The remarkable example of such diversity was the petroleum ether extract of $M$. scandens (PEMS) which in the direct free radical scavenging assay with DPPH had one of the lowest efficient scavenging capacity, whereas in terms of reducing power tested by phosphomolybdenum complex formation was among the better efficient extracts. Its haemoglobin glycosylation inhibition ability was also the third highest. On the other hand, petroleum ether extract of $A$. sanguinolenta (PEAS) showed least antioxidant activity in DPPH and haemoglobin glycosylation methods. Again, ethanol extract of $M$. scandens (EEMS) showed good free radical scavenging activity in DPPH assay, whereas the antioxidant activity of ethanol extract of $A$. sanguinolenta (EEAS) was moderate in all cases. Among the examined plants, it was also observed that $M$. scandens L. extracts had better antioxidant activity than that of $A$. sanguinolenta. The activities were close, identical in magnitude, concentration dependent and comparable with D- $\alpha$-tocopherol, ascorbic acid and rutin which were used as standard antioxidant compounds as per the procedure adopted.

Again, it was found that ethyl acetate and chloroform extract of both the plants had significant antidiabetic activity. The efficacy of the extract(s) was compared with standard drug, glibenclamide. The anti-hyperglycemic effect of the selected extract(s) might be due to an increase glucose consumption as well as significant protection against oxidative damaged in alloxanised diabetes mice ${ }^{29}$.

These results indicated a major complexity of involved mechanisms that could vary even the same plant with different extracts. The apparent discrepancy between the antioxidant properties assayed by various techniques ${ }^{30}$ and distribution of majority of the active antioxidants including flavonoids, tannins and polyphenolic compounds in different extracts (may be due to the polarity and partition co-efficient properties of

TABLE- 3

RESULTS OF THE PHOSPHOMOLYBDENUM ASSAY OF DIFFERENT EXTRACTS OF A. SANGUINOLENTA AND M. Scandens $s^{\mathrm{a}}$

\begin{tabular}{|c|c|c|c|c|c|c|c|c|c|c|}
\hline Extract & PEAS & CEAS & EAAS & EEAS & AEAS & PEMS* & CEMS & EAMS & EEMS & AEMS \\
\hline$(\mathrm{mg} / \mathrm{mL})$ & $40^{\circ} \mathrm{C} \quad 90^{\circ} \mathrm{C}$ & $40^{\circ} \mathrm{C} \quad 90^{\circ} \mathrm{C}$ & $40^{\circ} \mathrm{C} \quad 90^{\circ} \mathrm{C}$ & $40^{\circ} \mathrm{C} \quad 90^{\circ} \mathrm{C}$ & $40^{\circ} \mathrm{C} 90^{\circ} \mathrm{C}$ & $40^{\circ} \mathrm{C} 90^{\circ} \mathrm{C}$ & $40^{\circ} \mathrm{C} 90^{\circ} \mathrm{C}$ & $40^{\circ} \mathrm{C} \quad 90^{\circ} \mathrm{C}$ & $40^{\circ} \mathrm{C} 90^{\circ} \mathrm{C}$ & $40^{\circ} \mathrm{C} 90^{\circ} \mathrm{C}$ \\
\hline 0.25 & $\begin{array}{ll}1.6 \pm & .69 \pm \\
0.20 & 0.03\end{array}$ & $\begin{array}{cc}3.6 \pm & 4.09 \pm \\
0.07 & 0.11\end{array}$ & $\begin{array}{cc}3.4 \pm & 1.89 \pm \\
0.05 & 0.08\end{array}$ & $\begin{array}{|ll|}1.6 \pm & .99 \pm \\
0.03 & 0.02 \\
\end{array}$ & \begin{tabular}{cc|}
$1.2 \pm$ & $0.98 \pm$ \\
0.15 & 0.05
\end{tabular} & \begin{tabular}{cc|}
$2.1 \pm$ & $1.09 \pm$ \\
0.06 & 0.08
\end{tabular} & $\begin{array}{cc}2.5 \pm & 1.59 \pm \\
0.08 & 0.09\end{array}$ & $\begin{array}{cc}3.5 \pm & 2.00 \pm \\
0.13 & 0.08\end{array}$ & $\begin{array}{cc}2.6 \pm & 1.05 \pm \\
0.07 & 0.07\end{array}$ & $\begin{array}{cc}1.20 \pm & 3.6 \pm \\
0.09 & 0.03\end{array}$ \\
\hline 0.50 & $\begin{array}{c}1.28 \pm \\
0.10 \\
\end{array}$ & $\begin{array}{cc}7.0 \pm & 4.09 \pm \\
0.10 & 0.40\end{array}$ & $\begin{array}{cc}7.7 \pm & 4.09 \pm \\
0.30 & 0.14 \\
\end{array}$ & $\begin{array}{cc}2.5 \pm & 1.05 \pm \\
0.12 & 0.04 \\
\end{array}$ & $\begin{array}{cc}2.2 \pm & 1.09 \pm \\
0.11 & 0.09\end{array}$ & $\begin{array}{|cc|}4.6 \pm & 2.05 \pm \\
0.20 & 0.04 \\
\end{array}$ & \begin{tabular}{|cc}
$4.6 \pm$ & $3.09 \pm$ \\
0.10 & 0.10 \\
\end{tabular} & $\begin{array}{cc}6.6 \pm & 4.09 \pm \\
0.20 & 0.11\end{array}$ & $\begin{array}{cc}5.6 \pm & 2.04 \pm \\
0.11 & 0.04\end{array}$ & $\begin{array}{lc}3.6 \pm & 1.49 \pm \\
0.12 & 0.08 \\
\end{array}$ \\
\hline 0.75 & $\begin{array}{cc}7.8 \pm & 3.19 \pm \\
0.14 & 0.06\end{array}$ & $\begin{array}{cc}15.6 \pm & 4.09 \pm \\
0.50 & 0.07 \\
\end{array}$ & \begin{tabular}{|cc}
$16.0 \pm$ & $7.09 \pm$ \\
0.63 & 0.04 \\
\end{tabular} & $\begin{array}{cc}4.9 \pm & 2.09 \pm \\
0.05 & 0.02\end{array}$ & $\begin{array}{cc}3.6 \pm & 2.00 \pm \\
0.08 & 0.07\end{array}$ & \begin{tabular}{cc|}
$9.6 \pm$ & $4.09 \pm$ \\
0.25 & 0.11 \\
\end{tabular} & $\begin{array}{cc}9.5 \pm & 6.09 \pm \\
0.20 & 0.22\end{array}$ & \begin{tabular}{cc|}
$13.6 \pm$ & $7.59 \pm$ \\
0.23 & 0.09
\end{tabular} & $\begin{array}{cc}10.6 \pm & 4.09 \pm \\
0.16 & 0.16\end{array}$ & $\begin{array}{cc}6.6 \pm & 2.59 \pm \\
0.14 & 0.10\end{array}$ \\
\hline 1.00 & $\begin{array}{cc}10.26 \pm & 4.09 \pm \\
0.30 & 0.09\end{array}$ & $\begin{array}{cc}29.48 \pm 11.55 \pm \\
0.65 & 0.50\end{array}$ & $\begin{array}{cc}32.12 \pm 14.09 \pm \\
0.70 & 0.95\end{array}$ & \begin{tabular}{cc|}
$10.10 \pm$ & $5.90 \pm$ \\
0.85 & 0.20
\end{tabular} & $\begin{array}{|cc|}7.94 \pm & 3.36 \pm \\
0.16 & 0.08 \\
\end{array}$ & $\begin{array}{|cc|}19.23 \pm & 7.73 \pm \\
0.87 & 0.14\end{array}$ & $\begin{array}{cc}18.21 \pm 12.09 \pm \\
0.99 & 0.60\end{array}$ & $\begin{array}{cc}26.92 \pm & 15.45 \pm \\
0.31 & 0.42\end{array}$ & $\begin{array}{cc}20.26 \pm & 8.09 \pm \\
0.85 & 0.21\end{array}$ & $\begin{array}{cc}12.05 \pm & 5.27 \pm \\
0.30 & 0.21\end{array}$ \\
\hline
\end{tabular}


active constituents) were also very striking (Table-1). There are reports on the role of flavonoid, tannins and polyphenolic compounds as powerful antioxidants ${ }^{8,9,31,32}$. There are also reports on the role of tannins and polyphenolic compounds in antinociceptive activity ${ }^{33,34}$. Again, the plant extracts selected for the present investigation, demonstrated good antioxidant and anti-hyperglycemic action in the tested models (Tables 2 and 3). So, it can be assumed that flavonoids and tannins present in the selected extracts, as evidenced from phytochemical screening (Table-1), may be responsible for such antioxidant and antidiabetic activity. However, further studies are required for data accumulation, corresponding analyses of detailed chemical profiles of studied plants including isolation, identification, quantification of the active components responsible for such activities.

\section{Conclusion}

It is concluded from the present study that ethyl acetate and chloroform extract of $A$. sanguinolenta and $M$. scandens have significant free radical scavenging and antioxidant properties. From this study, some novel aspects come out for the therapeutic value of traditional Indian plants. The high antioxidant and antidiabetic potential of $A$. sanguinolenta and $M$. scandens can broaden their therapeutic applications towards the prevention of diseases associated with oxidants or free radicals. This study supports the claim by traditional medicine practitioners as antidiabetic, anticancer and antiinflammatory remedy.

\section{REFERENCES}

1. P.M. Basha and N. Madhusudhan, Biologia, 66, 187 (2011)

2 B. Halliwell, J.M.C. Gutteridge and C.E. Cross, J. Lab. Clin. Med. 119, 598 (1992).

3 M.B. Grisham and J.M. McCord, In ed.: A.E. Teylor, Chemistry and Cytotoxicities of Reactive Oxygen Metabolites; Biology of Oxygen Radicals; American Physiological Society, Bethesda, p. 1 (1986).

4 M. Kumar, A. Ahmad, P. Rawat and M.F. Khan, Fitoterapia, 81, 234 (2010).

5 R. Mahesh, H.W. Jung, J.H. Park and Y.K. Park, E-J. Chem., 8, 1451 (2011).

6 D.K. Pal, P. Maity and K. Samanta, Asian J. Chem., 22, 8246 (2010).
7 D.K. Pal, M. Kumar, P. Chakraborty and S. Kumar, Asian J. Chem., 20, 2479 (2008).

8 S. Sannigrahi, U.K. Mazumder, A. Mandal, D.K. Pal, S.L. Mishra and S. Roy, Nat. Prod. Commun., 5, 1239 (2010).

9 S. Sannigrahi, U.K. Mazumder, D.K. Pal, S. Parida and S. Jain, Iran. J. Pharm. Res., 9, 75 (2009).

10 J.R.S. Tabuti, K.A. Lye and S.S. Dhillion, J. Ethnopharmacol., 88, 19 (2003).

11 M.M. Alam, S.A. Alam, N.S. Mohammed, N.S. Juyena and M.A. Hashim, Pakistan J. Biol. Sci., 8, 740 (2005).

12 S.B. Kosalge and R.A. Fursule, J. Ethnopharmacol., 121, 456 (2009).

13 J. Buragohain, Fitoterapia, 79, 388 (2008).

14 M.C. Ysrael and K.D. Croft, Planta Med., 56, 268 (1990).

15 A. Bishayee and M. Chatterjee, Planta Med., 60, 110 (1994).

16 M.A. Mosaddik and K.M. Alam, J. Pharm. Pharmacol., 52, 1157 (2000).

17 P. Rajyalakshmi, K. Venkatalaxmi, K. Venkatalakshmamma, Y. Jyothsna, K.B. Devi and V. Suneetha, Plant Foods Human Nutri., 56, 225 (2001).

18 A. Ghani, Medicinal Plants of Bangladesh, Dhaka: The Asiatic Society of Bangladesh; edn. 2, p. 603 (2003).

19 B. Dinda, B. Ghosh, S. Arima, N. Sato and Y. Harigaya, Indian J. Chem., 42, 2223 (2004).

20 T. Nakamura, Y. Goda, S. Sakai, K. Kanda, H. Akiyama and M. Toyoda, Phytochemistry, 49, 2097 (1998).

21 D.K. Pal, K. Samanta and P. Maity, Asian J. Chem., 22, 2459 (2010).

22 S.B.Yadav, V. Tripathy, R.K. Singh and H.P. Pandey, Indian J. Pharm. Sci., 6, 477 (2000).

23 D.K. Pal and S.B. Nimse, Asian J. Chem., 18, 3004 (2006).

24 W. Pothitirat, M.T. Chomnawang, R. Supabphol and W. Gritsanapan, Fitoterapia, 80, 442 (2009)

25 A. Matkowski and M. Piotrowska, Fitoterapia, 77, 346 (2006).

26 P.R. Menezes, E.A. Schwarz and C.A.M. Santos, Fitoterapia, 75, 398 (2004).

27 S. Badole, N. Patel, S. Bodhankari, B. Jain and S. Bhardwaj, Indian J. Pharmacol., 38, 49 (2006).

28 J.S. Dunn and N.G. Mc Letchie, Lancet, 2, 384 (1943).

29 M. Aslan, N. Orhan, D.D. Orhan and F. Ergun, J. Ethnopharmacol., 128, 384 (2010).

30 D. Mantle, F. Eddeb and A.T. Pickering. J. Ethnopharmacol., 72, 47 (2000).

31 O. Firuzi, K. Javidnia, M. Gholami, M. Soltani and R. Miri, Iran. Nat. Prod. Commun., 5, 261 (2010).

32 T. Malliar, J. Drobna, J. Kraic, M. Maliarova and J. Jurovata, Biologia, 66, 96 (2011)

33 M.R. Vanu, S. Palanivelu and S. Panchanatham, Biol. Pharm. Bull., 29, 693 (2006).

34. A. Ozkan, A. Erdogan, M. Sokmen, S. Tugrulay and O. Unal, Biologia, 65, 990 (2010). 